\title{
PREFERENCIA POR LIBERDADE DE ESCOLHA MESMO QUANDO UMA DAS ALTERNATIVAS NUNCA (OU RARAMENTE) É ESCOLHIDA
}

\section{FREE-CHOICE PREFERENCE WHEN ONE ALTERNATIVE IS RARELY OR NEVER CHOSEN ${ }^{1}$}

\author{
A. Charles Catania \\ UNIVERSITY OF MARYLAND, BALTIMORE COUNTY (UMBC), UNITED STATES
}

\author{
Deisy das Graças de Souza \\ UNIVERSIDADE FEDERAL DE SÃO CARLOS, BRASIL
}

\author{
KOICHI ONO \\ KOMAZAWA UNIVERSITY, JAPAN
}

\begin{abstract}
RESUMO
Em uma situação de liberdade de escolha (escolha livre), duas ou mais respostas elegíveis para reforço estão concorrentemente disponíveis, como quando as bicadas de um pombo em qualquer um de dois discos pode produzir reforços em intervalo-fixo (FI). Em escolha forçada, uma única resposta é elegível para reforço, como quando as bicadas em um disco podem produzir reforços em FI, mas as bicadas em um segundo disco são colocadas em extinção (EXT). A liberdade de escolha tem sido tipicamente preferida à escolha forçada, quando ambas constituem os elos terminais de esquemas encadeados concorrentes ou de esquemas múltiplos encadeados concorrentes. Quando esquemas múltiplos encadeados concorrentes programam as condiçōes $\mathrm{A}$ e $\mathrm{B}$ para os elos terminais à esquerda e à direita, respectivamente, na presença de um dos estímulos do elo inicial, mas programam as posiçoes inversas para A e B nos elos terminais na presença do outro estímulo do elo inicial, as preferências podem ser determinadas, ao longo das sessóes, como diferenças nas taxas relativas nos elos iniciais. A questão neste experimento era se a preferência por escolha livre é demonstrável mesmo quando uma das alternativas quase nunca é escolhida ou é escolhida raramente. Uma história experimental sob esquemas múltiplos cujos componentes eram cadeias concorrentes, nas quais os elos terminais eram um mesmo esquema de FI, foi seguida pelo treino, independente dos elos iniciais, de FI 20-s (disco verde), FI 40-s (disco amarelo), e EXT (disco vermelho) nos elos terminais. Então, os esquemas múltiplos de cadeias concorrentes programaram os elos terminais de escolha livre com dois discos, verde (FI 20-s) e amarelo (FI 40-s), concorrentemente com elos terminais de escolha forçada, também com dois discos, um verde (FI 20-s) e outro vermelho (EXT). Esses elos terminais mantiveram o responder quase que exclusivamente no disco verde, quer o outro fosse amarelo ou vermelho, e todos os reforços foram produzidos por respostas no disco verde. Embora os reforços fossem iguais e a alternativa com o disco amarelo nunca ou quase nunca tivesse sido escolhida, o elo terminal com os discos verde e amarelo (escolha livre) foi preferido ao elo terminal com os discos verde e vermelho (escolha forçada).
\end{abstract}

Palavras-chave: escolha livre, escolha forçada, preferência, esquemas encadeados concorrentes, elos iniciais, elos terminais, operantes discriminados

\section{ABSTRACT}

In free choice, two or more responses eligible for reinforcement are concurrently available, as when a pigeon's pecks on either of two keys can produce fixed-interval (FI) reinforcers. In forced choice, only one eligible response is available, as when pecks on one key can produce FI reinforcers but extinction (EXT) is arranged for pecks on a second key. Free choice is typically preferred when pitted against forced choice in terminal links of concurrent-chain or multiple concurrent-chain schedules. When multiple concurrent-chain schedules arrange conditions A and B

\footnotetext{
This research was supported by US National Science Foundation Grants BNS85-06724 and BNS 86-07517 and PHS Grant MH-37256. We thank Rosie Mills, animal caretaker, and the several undergraduates who contributed to the conduct of this research. The data for Pigeons 70 and 72 were included in a poster, "Free-choice preference in the pigeon: Some new explorations of stimuli, parameters, and contingencies," presented at the Association for Behavior Analysis, Nashville, Tennessee, USA, May 1987. The first author may be contacted at: Department of Psychology, University of Maryland, Baltimore County (UMBC), 1000 Hilltop Circle, Baltimore, MD 21250 USA. Email: catania@umbc.edu.
} 
respectively for left and right terminal links during one initial-link stimulus but their reversal during a second initiallink stimulus, preferences can be determined within sessions as differences between relative initial-link rates. The experimental question was whether free-choice preference is demonstrable even with one free-choice alternative rarely or never chosen. A history of multiple concurrent-chains with equal single-FI terminal links was followed by training, independent of initial links, of FI 20-s (green key), FI 40-s (yellow key), and EXT (red key). Multiple concurrentchain schedules then pitted free-choice terminal links with green (FI 20-s) and yellow (FI 40-s) keys against forcedchoice terminal links with green (FI 20-s) and red (EXT) keys. These terminal links maintained responding almost exclusively on the green key whether the other key was yellow or red, and all reinforcers were produced by green-key responding. Even with reinforcers equal and with the yellow alternative rarely or never chosen, the green-yellow terminal link (free choice) was preferred to the green-red (forced choice) terminal link.

Key words: free choice, forced choice, preference, concurrent-chain schedules, initial links, terminal links, discriminated operants

As concurrent-chain schedules are typically arranged for pigeons, two keys are concurrently available in initial links. According to equal but independent random-interval or variable-interval (RI or VI) schedules, pecks on these keys respectively produce separate terminal links during which pecks may produce food. To the extent that one initial-link key maintains more pecking than the other, the terminal link produced by pecks on that key is said to be preferred to the terminal link produced by pecks on the other. Preference is usually expressed in terms of relative rate of responding: left initial-link responses divided by total initial-link responses. For example, an outcome with two-thirds of the initial-link pecks on the left and one-third on the right might be discussed as a two-to-one preference for left terminal links over right terminal links.

Concurrent-chain schedules rather than simple concurrent schedules have been procedures of choice in studies of preference because the latter schedules confound preference with the variables that determine the rates of the concurrent responses. For example, with concurrent schedules that differentially reinforce high and low rates of responding (DRH and DRL), relative response rates are determined mainly by the high-rate and low-rate contingencies and therefore cannot be taken as preferences. Concurrent-chain schedules, however, separate preferences for different conditions, in initial links, from the contingencies that maintain responding during those conditions, in terminal links.

Within concurrent-chain procedures, preferences have been demonstrated for free-choice conditions over forced-choice conditions, with free choice defined as the availability of two or more operant classes maintained by reinforcers and forced choice defined as the availability of only a single such class (Catania, 1975, 1980; Catania \& Sagvolden, 1980). For example, if pecks on either a green or a yellow key (GY) produce food at the end of a fixed interval (FI) whereas pecks on only the green key of a green and red pair (GR) produce food at the end of an identical fixed interval, a pigeon will prefer the GY pair over the GR pair even if total responses on the two keys and time until food delivery are essentially the same in the two conditions. The former consists of two reinforced classes, pecks on either $\mathrm{G}$ or $\mathrm{Y}$, whereas the latter consists of only one reinforced class, pecks on $G$, because pecks on $\mathrm{R}$ are never reinforced. A variety of procedures have shown that free-choice preferences are not reducible to stimulus variables such as key colors or key locations. The additional finding that preference does not reliably increase with increasing numbers of alternatives makes accounts of the free-choice preference that appeal to number of conditioned reinforcers and other stimulus effects implausible and creates difficulty for the hypothesis that the free-choice preference is acquired through a history in which the availability of more than one alternative has been advantageous.

In the example above, equal FI schedules are arranged for $\mathrm{G}$ and for $\mathrm{Y}$, and therefore pecks are likely to be emitted on both keys and reinforcers are likely to be delivered according to both schedules. But if the FI schedules are unequal and the terminal link ends with the first reinforcer that is delivered, pecks are likely to be 
emitted mainly on the key with the shorter FI and only reinforcers scheduled by its shorter FI are likely to be delivered. For example, with FI 20-s during G and FI 40-s during Y, the FI 20-s schedule is likely to be completed on $\mathrm{G}$ before any pecks are emitted on Y (cf. Catania, Sagvolden, \& Keller, 1988).

In a human example, consider the choice between two restaurants, one of which serves both seafood and meat and the other of which serves only seafood. If, when given the choice, a particular diner almost always orders seafood rather than meat, would that diner nevertheless show some preference for the first restaurant over the second, even though the diner is likely to eat the same course in either restaurant? (For the present purposes, it is sufficient for the diner to show a slight preference; we should not expect an exclusive one.) This example, of course, makes the unlikely assumption that the restaurants are otherwise equal in the quality of the food and other respects. It is also useful to note that when we consider the human example we are likely to invoke human verbal behavior that often precedes choices. Demonstrations with nonhuman analogues, however, suggest that accounts in terms of simpler determinants of preference may be adequate. For example, in his discussion of the aversiveness of overchoice, or large numbers of alternatives, Schwartz (2004) fails to acknowledge the relevant literature on nonhuman preferences and appears to attribute the phenomenon predominantly to human social practices.

Let us now consider an experimental pigeon analogue of this human example. It consists of three stages. First, we arrange concurrent chains with separate but equal FI terminal links in the presence of Y and R; this establishes concurrent-chain performance and also incidentally assesses color preference. Next, independently of the chains, we separately arrange FI 20-s in G, FI 40-s in Y, and EXT 40-s (extinction) in R. Finally, we reinstate the chains, combining $G$ and $Y$ in one terminal link and $G$ and $R$ in the other. Whether the second stimulus is Y (FI 40-s) or R (EXT 40-s), pigeons will typically respond mostly on $G$ and will therefore exclusively produce the FI 20-s reinforcer in both types of terminal links. Will they prefer free-choice terminal links (GY) over forced-choice terminal links (GR) even though they respond rarely on and never produce one of reinforcers $(\mathrm{Y})$ available in the freechoice terminal link?

This experimental question was examined using multiple concurrent-chain schedules rather than concurrent-chain schedules in which only one pair of initial-link schedules produces terminal links. When free choice in one terminal link is pitted against forced choice in another, the magnitude of preference as measured in terms of relative initial-link response rates (left divided by total) is typically 0.1 or less. Such small preferences are particularly susceptible to masking by shifts in baseline (relative initial-link rates when terminal links are equal) or by other sources of variability.

Multiple concurrent-chain schedules arrange a pair of terminal links during one initial-link stimulus and a different pair (usually the reversal of the first) during a second initial-link stimulus. For example, left and right initial-link pecks that produce respective A and B terminal-link conditions during one stimulus can produce respective $\mathrm{B}$ and $\mathrm{A}$ terminal-link conditions during the other. Multiple concurrent-chain schedules, with components each consisting of a pair of concurrent chains, reduce the impact of shifts in baseline as a source of variability and also speed determinations of preference by arranging A and B and their reversal within each session. This methodology was used to answer the experimental question of whether free-choice preference can be demonstrated even with a history in which, given the opportunity for a choice between the two free-choice alternatives, one of them has rarely or never been chosen.

\section{METHOD}

\section{Subjects and Apparatus}

Five experimentally naive White Carneaux pigeons were maintained under standard laboratory protocols for animal care and use. When not in the experimental space, the pigeons were individually housed in a facility with a 
12-hr-on 12-hr-off light-dark cycle and were held at about $80 \%$ of free-feeding weights. Each pigeon had an experimental history consisting only of the shaping of pecks on a white key.

Unless otherwise specified, the details of apparatus and procedure were as described in Cerutti and Catania (1986); see also Ferster and Skinner (1957). The experimental panel included a horizontal bottom row of two keys for which initial links were arranged and a horizontal top row of three keys for which terminal links were arranged. Keys were matched to operate with a minimum force of about 0.20 N. Reinforcers were Purina pigeon pellets presented by a standard Gerbrands feeder centered beneath the keys. The duration of feeder operations was 4-s, during which the feeder was lit and other lights in the chamber were off.

Stimuli were displayed by in-line display units (Industrial Electronics Engineers Model 10) mounted behind each key. Initial-link stimuli on the two bottom keys consisted of a pattern of circles or a pattern of plus signs. In circle components, three 6-mm diameter white circles in a base-up triangular configuration were projected on each key; in plus components, three white plus signs, 6$\mathrm{mm}$ high and 6-mm wide with arms $1.5-\mathrm{mm}$ thick, were projected in the same triangular configuration. The terminal-link stimuli that appeared on the top left key or the top right key were yellow (amber) or red; the stimulus that appeared on the top middle key was green. A houselight was lit during initial links and off during terminal links. Scheduling and recording were arranged by an Apple IIe computer connected to the chamber by a John Bell Engineering 6522 Parallel Interface and solidstate switching circuitry.

The number of pigeons in this study was limited by the space available for housing experimentally naive pigeons. Time was an additional constraint. The procedures described here were conducted just prior to what was to have been a brief temporary closing of the laboratory for upgrading of temperature control systems and other utilities but the closing lasted for roughly three years.

\section{Procedure}

Sessions typically consisted of 20-min of initial links, with occasional minor adjustments to maintain appropriate body weights while allowing the pigeons to earn all or most of their daily food ration in the experimental chamber. Given the parameters of the current research, overall session duration was typically less than one hour. The procedures included three main conditions: (1) initiallink training with terminal links consisting of a single FI on yellow $(\mathrm{Y})$ or a single FI on red (R), with schedule values gradually increased to FI 40-s; (2) single-key terminal-link-only training with FI 20-s on green (G), FI-40-s on Y, and EXT 40-s on R; and (3) multiple concurrentchain conditions in which terminal links pitted free choice (GY: FI 20-s and FI 40-s) against forced choice (GR: FI 20-s and EXT 40-s).

1. Initial-Link Training. Random alternations between the two multiple-schedule components (circles and plus signs) occurred with a probability of .50 after every thirty initial-link seconds. During both components, pecks on initial-link keys produced separate terminal links according to equal but independent concurrent randominterval (RI) schedules the durations of which were gradually increased over sessions to RI 40-s: setups were incremented every second with a probability of .025 and were decremented whenever an initial-link peck produced a terminal link. In other words, the RI schedule for each initiallink key continued to operate even when one or more terminal links had already been set up for subsequent pecks on that key; terminal links not yet produced accumulated separately within each multiple-schedule component (circles and plus signs) but were not saved from one session to another. The advantage of this procedure over stopping the RI scheduling after a setup had been arranged was that it minimized differences between scheduled and obtained rates of reinforcement. During initial links, terminal-link keys were dark and the first peck on one initial-link key after a peck on the other could not produce a terminal link (COR or changeover ratio). The houselight was on during initial but not during terminal links. 
During circle components left initial-link pecks produced yellow FI terminal links on the top left key and right initial-link pecks produced red FI terminal links on the top right key; during plus components, left initiallink pecks produced red FI terminal links on the top left key and right initial-link pecks produced yellow FI terminal links on the top right key. During training, the terminal-link schedules were gradually increased in duration to FI 40-s. These terminal links were maintained for different numbers of sessions for each pigeon, typically for eight to ten weeks but depending also on visual estimates of the stability of initial-link and terminal-link performances.

2. Terminal-Link Training. In these sessions, initiallink keys were always dark and terminal links on the top keys were respectively produced by two independent random-time 40-s schedules (RT $40 \mathrm{~s}$, with opportunities for terminal links sampled every second with a probability of .025). With this arrangement, the conditions that were to serve later as terminal links were presented with a temporal distribution similar to what would be produced when initial links were reinstated. The houselight was on during times between terminal links.

Three kinds of terminal links were arranged, each on a single key: FI 20-s (G) on the top middle key, FI 40$s(\mathrm{Y})$ on the top left or right key, and EXT 40-s (R) on the top left or right key (in EXT 40-s, the red key turned off after $40 \mathrm{~s}$, independently of whether any pecks had occurred on the key). Whenever RT 40-s scheduled a terminal link, the respective probabilities of these conditions were 0.50 for FI 20-s (G), 0.25 for FI 40-s $(\mathrm{Y})$, and 0.25 for EXT 40-s (R). This procedure was maintained for at least three weeks of daily sessions and until both EXT 40-s $(\mathrm{R})$ response rates were near zero and FI 20-s (G) response rates were consistently higher than FI 40-s $(\mathrm{Y})$ response rates over several consecutive sessions for Pigeons 70 and 72; it was maintained for roughly sixty sessions and the same rate criteria for Pigeons 40, 41 and 43 .

3. Multiple concurrent-chain conditions with freechoice and forced-choice terminal links. In this condition initial links were reinstated and the terminal links of Condition 2 were arranged concurrently: either FI 20-s (G) with FI 40-s (Y) or FI 20-s (G) with EXT 40-s (R). With GR terminal links, the EXT (R) key turned off at the same time as the $G$ key, i.e., when a peck on $G$ produced the FI reinforcer. The details of initial and terminal links and schedules were otherwise as in Condition 1. Each terminal link ended with the first reinforcer delivery; in practice, this was always one produced by an FI 20-s $(\mathrm{G})$ peck. With some pigeons, a further condition examined FI 20-s (G) alone versus FI 20-s (G) EXT 40$s(\mathrm{R})$ or, in other words, forced choice in both terminal links, and a final condition examined the subsequent return to free-choice (GY) forced-choice (GR) conditions.

If a constant and immediate reinforcing effect produced by the onset of free-choice contingencies summates with the effect of the FI food reinforcer at the end of the terminal link, then free-choice onset will contribute more to the total reinforcing effect of a terminal link, and therefore will produce larger initial-link shifts in preference, as the delay to the reinforcer at the end of the FI increases. For that reason, the longer FI during yellow was set at $40 \mathrm{~s}$ rather than at a shorter value, even though a shorter value would have allowed shorter daily sessions.

\section{RESULTS}

Figure 1, which presents data from five pigeons, summarizes preferences for terminal links as differences between the relative rates in each multiple concurrentchain component. Suppose that preference for A on the left over $\mathrm{B}$ on the right during one schedule component is 0.64 (64\% of initial-link pecks are emitted on the left, which is the key producing $A$ ), and that preference for $B$ on the left over $A$ on the right during the other component is 0.28 ( $72 \%$ of initial-link pecks are emitted on the right, which is the key producing A). The difference between these two relative rates is 0.36 , suggesting a baseline somewhere between them, roughly at 0.46 , relative to which $A$ on the left or $A$ on the right creates a preference 
shift. For convenience, preferences are presented here as differences in the two relative rates $(\mathrm{L} /[\mathrm{L}+\mathrm{R}])$. Strictly, they might be calculated as half that difference (i.e., in each direction from the estimated baseline), but such a calculation assumes that asymmetrical shifts are equivalent. That assumption may be inappropriate. For example, given a baseline at 0.30 , a shift to 0.15 in one direction is half of the maximum possible shift to 0.00 , but one in the other direction, to 0.45 , is less than one-quarter of the maximum possible shift to 1.00 .

Initial-link training (Condition 1) provided a baseline of multiple concurrent-chain performance against which later preferences could be compared. Color preferences were inconsistent for Pigeons 70, 72 and 41, but Pigeon 40 showed a consistent red (R) preference and Pigeon 43 showed a fairly consistent yellow $(\mathrm{Y})$ preference. When free-choice (GY) and forced-choice (GR) terminal links were arranged in Condition 3, after FI 20-s (G), FI 40-s (Y) and EXT (R) had been separately established during Condition 2, all pigeons responded almost exclusively on $\mathrm{G}$ and preferences shifted toward GY, the free-choice component, though the shifts for Pigeons 70 and 72 were small in magnitude and that for Pigeon 43 was transient.

When the free-choice (GY) terminal link was changed to forced choice $(\mathrm{G})$ by removing the yellow key, preferences moved toward their levels in Condition 1, though with increasing variability for Pigeon 41. Increases in variability

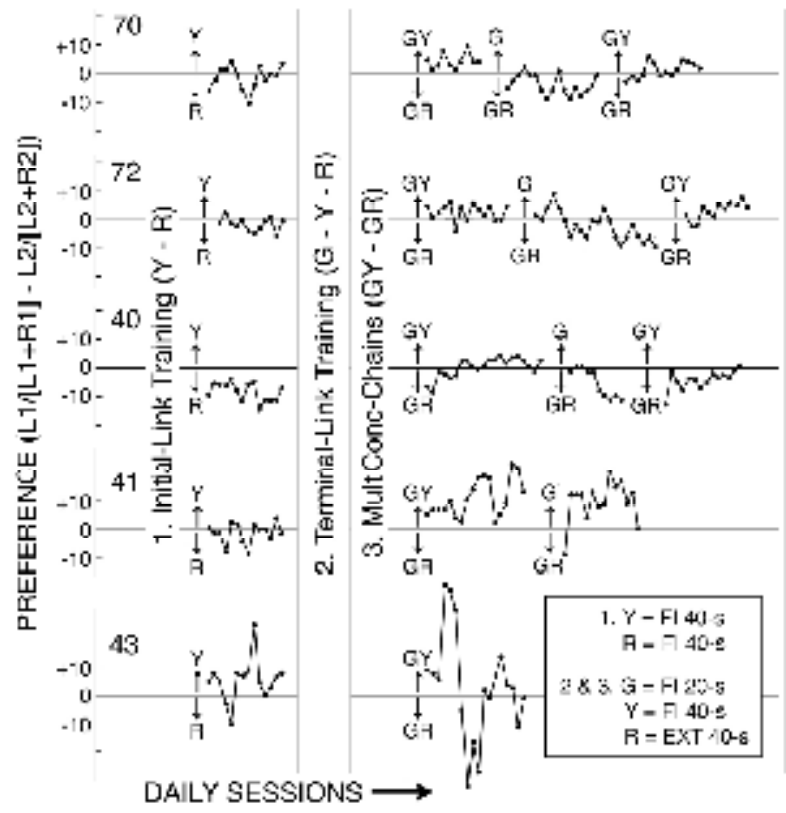

Figure 1. Preferences over successive conditions for five pigeons. The $\mathrm{x}$-axis shows consecutive sessions within a condition (horizontal spaces between conditions are arbitrary). The $\mathrm{y}$-axis shows magnitude of preference as one-half the difference between the relative response rates $(\mathrm{L} /[\mathrm{L}+\mathrm{R}])$ in each of the two types of initial links (circles or plusses). An up or down shift of data indicates a shift of preference toward the terminal-link contingency labeled by the arrow pointing in that direction (e.g., Y or R). In condition 1, initial-link responses given circles or plusses produced terminal links with FI 40-s arranged for either a single yellow key $(\mathrm{Y})$ or a single red key (R); color did not appear to be a major determinant of preference for Pigeons 70,72 and 41 , but Pigeon 40 showed a consistent $\mathrm{R}$ preference and Pigeon 43 a fairly consistent $Y$ preference. In condition 2, independent of the concurrent-chain schedules, single-key training arranged FI 20-s on green (G), FI 40-s on yellow (Y) and 40 s of EXT on red (R). In condition 3, the concurrent-chain schedules pitted free-choice terminal links that combined green and yellow keys (GY) against forced-choice terminal links that combined green and red keys (GR); for four of the five pigeons this was followed by G versus GR terminal links and then, for three of these, a return to GY versus GR. Terminal-link performances in condition 3 consisted almost entirely of green-key responding, with all reinforcers produced by FI 20-s green-key pecks. The data are on the whole consistent with preference for free-choice GY terminal links over forced-choice GR terminal links, though performance was variable in the later sessions for Pigeon 41 and highly variable across all the GY-GR sessions for Pigeon 43. 
during and after the $G$ versus GR condition precluded the further assessment of preferences for Pigeons 41 and 43 . For the remaining three pigeons, preferences during the $G$ versus GR conditions provided no suggestion that the extinction stimulus, $\mathrm{R}$, had acquired aversive properties. When the GY versus $\mathrm{GR}$ conditions were reinstated for these three pigeons, their preferences again moved in the direction of free-choice (GY) terminal links, even though no Y reinforcers were produced when $G$ and $Y$ were both available, and even though Y responses, like $\mathrm{R}$ responses in GR, were emitted at a very low rates (typically well below $1 \%$ of the rates maintained on G). During all of its GY versus GR sessions, Pigeon 41 emitted no pecks on either Y or R during terminal links. Thus, the GY and GR terminal links produced roughly equal performances (FI 20-s responding on a single key, G), though the recent histories for Y (FI 40-s) and R (EXT) differed. The magnitudes of the free-choice preferences observed here were comparable to those observed in previous research on free choice versus forced choice (e.g., Catania, 1980). Note also that by simple binomial calculations the probability of ten shifts in an appropriate direction out of the twelve transitions arranged during Condition 3 in Figure 1 (all but the G versus GR shift for Pigeon 41 and the single GY versus GR shift for Pigeon 43) is statistically significant at well below the 0.05 level.

Data from two other pigeons that served in pilot versions of these procedures have been excluded from the figure. In one case, Pigeon 38, the data were similar to those of Pigeon 40 but the first few sessions of the GY versus GR condition were marred by several equipment and programming problems. In the other case, Pigeon 35 , the pigeon's performance included extreme preferences for the left initial-link key that masked effects of terminal links; eventually this key preference was overcome and free-choice (GY) preference was obtained, but only after a complex experimental history.

\section{Discussion}

When multiple concurrent-chain schedules pitted free-choice terminal links with green (FI 20-s) and yellow
(FI 40-s) keys against forced-choice terminal links with green (FI 20-s) and red (EXT) keys, the terminal links maintained responding almost exclusively on the green key whether the other key was yellow or red, and all reinforcers were produced by green-key responding. Even with reinforcers equal and with the yellow alternative rarely or never chosen, the green-yellow terminal link (free choice) was preferred to the green-red (forced choice) terminal link.

The magnitude of the free-choice preference was small. Preferences of 0.525 with free-choice on the left and 0.475 with free-choice on the right, yielding a difference of 0.05 that is in the range of the data of Figure 1 , are roughly comparable to the preferences that might be observed in pitting 52.5 reinforcers/hour arranged for one key against 47.5 reinforcers/hour arranged for the other, yielding a difference of 5 reinforcers/hour. But if the free-choice preference is ubiquitous though small and if it operates over a range of contingencies that include those in which one or more alternatives is rarely chosen, it may have large cumulative effects on behavior, especially because it may be relatively strong in some contexts (e.g., when other reinforcers are weak as a result of satiation).

These findings are one more reminder of the ubiquity of operants as functional units of behavior. The availability of an alternative correlated with reinforcers is preferable to its unavailability, even if that alternative is rarely chosen. Colloquially we might say that even if we do not often choose an alternative, it is usually nice to know it is there.

In other words, the critical behavioral units in these performances are functional and not topographical. In experiments involving free-choice preference, keys on which pecks do not produce reinforcers (e.g., inoperative dark keys or keys correlated with extinction) do not become conditional reinforcers and therefore are ineffective as alternatives; they also do not maintain behavior, and therefore are ineffective as components of an operant class. A two-key terminal link in which pecks on either key can produce reinforcers is a free-choice terminal link, but a 
terminal link in which pecks on only one of the two keys can ever do so is not. The functional units are the different keys, each correlated with particular stimuli and contingencies. These units are discriminated operants (Skinner, 1938), and to demonstrate a free-choice preference is to demonstrate a preference for the availability of two or more operant classes over a single operant class.

Variability is a factor in choice and providing two keys instead of one key offers a greater opportunity for variable responding (cf. Neuringer, 2002). But a large literature on preferences in concurrent-chain procedures (e.g., Davison \& McCarthy, 1988) has shown that temporal and other variables are typically far more potent than response variables. Furthermore, experiments pitting key size against number of keys have shown that the number of available keys, whether large or small, is a more potent determinant of preference than the area available for pecking (Catania, 1983; Catania \& Reich, 1982; Cerutti \& Catania, 1997).

This conclusion was supported in Condition 3 of the present experiment, in that differences in terminallink responding were inconsistently correlated with initiallink preferences even with responding almost exclusively on the green FI key. Over blocks of successive sessions, changes in relative initial-link rates were sometimes correlated with changes in relative terminal-link rates, but over the experiment as a whole, as in prior research, those correlations were transient in both magnitude and direction. It is appropriate to conclude that the preferences were determined by properties of the terminal-link contingencies rather than by properties of the responding produced by those contingencies.

\section{A METHODOLOGICAL NOTE ON EXPERIMENTAL}

\section{PREPARATIONS}

Conditions varied across the pigeons shown in Figure 1 and the two pigeons whose data were excluded from that figure. In evaluating such cases, comparison with experimental procedures in biology is instructive. Many experiments in biology involve preparations set up to study phenomena of biological interest. Preparations that are not viable are discarded. These discarded instances are not typically reported along with the data from effective preparations. The present multiple concurrent-chain schedules are also instances of preparations. As such, Pigeons 70, 72 and 40 remained viable throughout the study, but the viability of Pigeons 41 and 43 was not sustained and that of Pigeons 38 and 35 was not really achieved at all.

Even well-established preparations must be tested occasionally against variables with known effects, to insure that individual performances remain sensitive to the variables of interest throughout the course of the experiment. Complex preparations such as multiple concurrent-chains are sometimes fragile and sometimes it is more efficient to create a new preparation than to make an old one viable again. For example, if differences among the reinforcing effectiveness of terminal links are small (consider the identical FI contingencies in the $\mathrm{Y}$ and $\mathrm{R}$ terminal links of Condition 1), the contingencies that maintain attention to the initial-link multiple schedule stimuli will be weak and performances may lose their sensitivity to differences in the properties of terminal links. In the conduct of such experiments, alertness to the ongoing viability of preparations is probably a more important consideration than the amassing of larger numbers of subjects to satisfy the requirements of statistical tests.

\section{REFERENCES}

Catania, A. C. (1975). Freedom and knowledge: An experimental analysis of preference in pigeons. Journal of the Experimental Analysis of Behavior, 24, 89-106.

Catania, A. C. (1980). Freedom of choice: A behavioral analysis. In G. H. Bower (Ed.) The psychology oflearning and motivation (vol. 14, pp. 97-145). New York: Academic Press.

Catania, A. C. (1983). Is not-responding behavior? Behavioral and Brain Sciences, 6, 321-322.

Catania, A. C., \& Reich, G. M. (1982). Key area versus number of keys in the pigeon's preference for free choice over forced choice: A preliminary study. Revista Mexicana de Analisis de la Conducta, 8, 127-132. 


\section{A. C. CATANIA ET AL.}

Catania, A. C., \& Sagvolden, T. (1980). Preference for free choice over forced choice in pigeons. Journal of the Experimental Analysis of Behavior, 34, 77-86.

Catania, A. C., Sagvolden, T., \& Keller, K. J. (1988). Reinforcement schedules: Retroactive and proactive effects of reinforcers inserted into fixed-interval performances. Journal of the Expe-rimental Analysis of Behavior, 49, 49-73.

Cerutti, D. T., \& Catania, A. C. (1986). Rapid determinations of preference in multiple concurrentchain schedules. Journal of the Experimental Analysis of Behavior, 46, 211-218.

Cerutti, D. T., \& Catania, A. C. (1997). Free-choice preference in pigeons: Key number versus key area.
Journal of the Experimental Analysis of Behavior, 68, 349356.

Davison, M., \& McCarthy, D. (1988). The matching law: A research review. Hillsdale, NJ: Erlbaum. Ferster, C. B., \& Skinner, B. F. (1957). Schedules of reinforcement. New York: Appleton-Century-Crofts.

Neuringer, A. (2002). Operant variability: Evidence, functions, and theory. Psychonomic Bulletin and Review, 9, 672-705.

Schwartz, B. (2004, April). The tyranny of choice. Scientific American, 290(4), 70-75.

Skinner, B. F. (1938). The behavior of organisms. New York: Appleton-Century-Crofts. 